\title{
Empreendedorismo feminino em época de pandemia: um estudo de caso no ramo alimentício na cidade de Itapagipe-MG
}

Female entrepreneurship in pandemic times: a case study in the food business in the city of Itapagipe-MG

Emprendimiento femenino en tiempo de pandemia: un estudio de caso en la industria alimentaria en la ciudad de Itapagipe-MG

Stefany Duarte Costa Ferreira ORCID: https://orcid.org/0000-0002-0465-4234 Universidade do Estado de Minas Gerais, Brasil

E-mail: stefanyd1999@gmail.com

Elizangela Cristina Begido Caldeira ORCID: https://orcid.org/0000-0002-2144-1273 Universidade do Estado de Minas Gerais, Brasil

E-mail: elizangelacb@yahoo.com.br

Josney Freitas Silva

ORCID: https://orcid.org/0000-0002-9349-4497 Universidade do Estado de Minas Gerais, Brasil

E-mail: josney.silva@uemg.br

Marildo Domingos da Silva

ORCID: https://orcid.org/0000-0003-4142-1867 Universidade do Estado de Minas Gerais, Brasil E-mail: marildo.silva@uemg.br

Carlos Alípio Caldeira

ORCID: https://orcid.org/0000-0002-1403-0310 Universidade do Estado de Minas Gerais, Brasil E-mail: carlos.caldeira@uemg.br

\begin{abstract}
Resumo
Com a pandemia houve grandes mudanças em todos os setores sociais. A pesquisa trata de investigar quais os motivos relacionados ao aumento do empreendedorismo feminino em período pandêmico, em específico no ramo alimentício, na cidade de Itapagipe-MG. Este estudo tem como objetivo levantar fatos relevantes sobre a propagação deste empreendimento. A metodologia empregada é caracterizada pela abordagem qualitativa, conduzida de forma exploratória, voltada para um estudo de caso, onde visa conhecer e analisar sobre o assunto, através da aplicação de questionário. Ao finalizar, foi possível compreender alguns relatos sobre a situação presente, sendo dispostas duas possíveis respostas a essa problemática: empreender por oportunidade ou por necessidade. A pesquisa mostrou dados importantes, como nível de escolaridade, estado civil, número de filhos e ganho mensal das envolvidas. De acordo com a análise, foi possível concluir que a maior parte das mulheres começaram a empreender por necessidade, por motivos de renda extra, independência, autonomia, disponibilidade de tempo e amar empreender.
\end{abstract}

Palavras-chave: Empreendedorismo feminino; Pandemia; Oportunidade x necessidade; Ramo alimentício.

\begin{abstract}
With the pandemic there have been major changes in all social sectors. The research is to investigate the reasons related to the increase in female entrepreneurship in the pandemic period, in particular in the food sector, in the city of Itapagipe-MG. This study aims to raise relevant facts about the spread of this enterprise. The methodology used is characterized by the qualitative approach, conducted in an exploratory way, focused on a case study, where it aims to know and analyze the subject, through the application of a questionnaire. Finally, it was possible to understand some reports about the present situation, and two possible answers to this problem were arranged: undertake by opportunity or necessity. The research showed important data, such as level of education, marital status, number of children and monthly gain of those involved. According to the analysis, it was possible to conclude that most women began to undertake for necessary.
\end{abstract}

Keywords: Female entrepreneurship; Pandemic; Opportunity vs. need; Food industry. 


\section{Resumen}

Con la pandemia hubo grandes cambios en todos los sectores sociales. La investigación busca investigar las razones relacionadas con el aumento del emprendimiento femenino en período de pandemia, específicamente en la industria de alimentos, en la ciudad de Itapagipe-MG. Este estudio tiene como objetivo plantear hechos relevantes sobre la propagación de esta empresa. La metodología utilizada se caracteriza por un enfoque cualitativo, realizado de forma exploratoria, centrado en un estudio de caso, donde se pretende conocer y analizar el tema, a través de la aplicación de un cuestionario. Al final, fue posible comprender algunos relatos sobre la situación actual, con dos posibles respuestas a este problema: emprender por oportunidad o por necesidad. La investigación arrojó datos importantes, como el nivel educativo, el estado civil, el número de hijos y los ingresos mensuales de los involucrados. De acuerdo con el análisis, fue posible concluir que la mayoría de las mujeres comenzaron a emprender por necesidad, por razones de ingresos extra, independencia, autonomía, disponibilidad de tiempo y amor por emprender.

Palabras clave: Emprendimiento femenino; Pandemia; Oportunidad x necesidad; Industria alimentaria.

\section{Introdução}

O empreendedorismo feminino é definido por mulheres que estão envolvidas na tomada de decisão de negócios independentes relacionadas com a gestão empresarial. O papel da mulher empreendedora é significativa para a contribuição da economia do país, reduzindo a pobreza, aumentando as receitas e, ocorrendo o desenvolvimento econômico local (Hapsari et al., 2018).

As micro, pequenas e médias empresas possuem papel fundamental para o desenvolvimento econômico brasileiro, essa categoria de empresas são as que mais geram emprego para a população brasileira (Soares, 2020).

De acordo com o relatório publicado pelo programa de Monitoramento de Empreendedorismo Global (GEM), houve um aumento significativo na taxa de empreendedores iniciais no Brasil. Os motivos agregados a esse crescimento podem ser relacionados a retomada da economia e do otimismo no meio empresarial e financeiro e, pela redução nas taxas de desemprego, mantendo ainda muitas incertezas sobre as opções de ocupação e de obtenção de renda para a população (GEM, 2019).

Diante de uma sociedade com crescimento participativo das mulheres no mercado de trabalho, percebe-se destaque com o público feminino no setor do empreendedorismo. Analisando o cenário atual, busca-se investigar esse público em destaque com o clima de incertezas, medo e insegurança passado nos últimos meses com a pandemia da COVID-19 (Lacerda, 2020).

As mulheres vêm lutando há anos por igualdade social e espaço no mercado. Contribuem para o crescimento da economia e para a criação de empregos e, transformam as relações sociais. Empresárias empoderadas podem influenciar e inspirar outras mulheres, ajudando a superar obstáculos e desafios da vida.

Segundo a GEM - Global Entrepreneurship Monitor, os fatores que levaram a se envolver com atividades empreendedoras, se dividem em empreendedorismo por oportunidade e por necessidade. São considerados empreendedores por oportunidade aqueles que afirmam ter iniciado o negócio principalmente pelo fato de terem percebido uma oportunidade em um ambiente. Já o empreendedor por necessidade é aquele que afirma ter iniciado o negócio pela ausência de alternativas para a geração de ocupação e renda (GEM, 2017, p. 9).

As condições atuais aliadas ao processo de globalização, têm exigido grande esforço de se adequar à realidade econômico-financeira apresentada. E por circunstâncias desse ambiente econômico, as mulheres tiveram que recorrer a outros meios de remuneração. Considerando as oportunidades e necessidades impostas por esse cenário, esse gênero começou a empreender e se submeteu ao desafio do mundo dos negócios, conquistando maior espaço no mercado (GEM, 2019, p. 13-15).

A grande maioria dessas mulheres são motivadas e influenciadas por enfrentar diversas dificuldades, decorrentes do desemprego ou de péssimas condições de trabalho formal. Também conseguem enxergar o empreendedorismo como 
oportunidade para o aumento da renda e a conquista de independência financeira. Com isso, essas mulheres investem em seu próprio trabalho informal, proporcionando condições mais favoráveis.

Com a pandemia algumas pessoas tiverem que se reinventar diante do mercado de trabalho e, outras aproveitaram esse período para começar um novo negócio. O presente trabalho busca compreender os principais motivos pelos quais levaram as envoltas na pesquisa a começar o seu empreendimento na cidade de Itapagipe perante a Covid-19.

\section{Metodologia}

A pesquisa foi conduzida de forma exploratória, com pesquisa de campo, caracterizada pela abordagem qualitativa. Realiza-se uma coleta de dados sobre a determinada situação que está sendo investigada, mediante o contato entre entrevistado e pesquisador, através de entrevista ou aplicação de um questionário/formulário desenvolvido (Lüdke et al., 1986). O método utilizado para conseguir uma amostra de 08 pessoas envolvidas, decorreu pela ferramenta do Instagram, onde foi aberto um espaço para que houvesse sugestões de mulheres empreendedoras do próprio negócio. Uma pequena parcela da população identificou algumas empreendedoras que começaram seu engajamento no ramo alimentício, em específico, durante a pandemia. Após conseguir essa amostra, a pesquisa foi realizada por meio de um formulário com 8 perguntas abertas e fechadas, aplicado via internet.

\section{Referencial Teórico}

\subsection{Empreendedorismo}

De acordo com Maximiano, o espírito empreendedor está associado a pessoas realizadoras, que estimulam recursos e correm riscos para alcançar sua própria empresa. A palavra "empreendedor" denomina a pessoa que cria uma organização de negócios (Maximiano, 2011, p. 1).

Empreender se refere à capacidade que uma pessoa tem de identificar problemas e oportunidades, desenvolvendo soluções e investindo em recursos para a criação de algo novo para a sociedade.

A necessidade de realizar um empreendimento, ser o próprio gestor, sair da rotina, ter uma renda maior, desenvolver um produto/serviço que traga benefícios para a sociedade, são alguns dos motivos que levam pessoas a ter o seu próprio negócio (Degen, 1989, p.15).

O perfil empreendedor sabe que para ter sucesso no seu negócio, depende principalmente de sua iniciativa. A oportunidade de iniciar um negócio, produz um sentimento de realização e satisfação ao conseguir o que se almeja (Maximiano, 2011, p. 6).

Segundo o Global Entrepreneurship Monitor, a taxa de empreendedorismo total no Brasil foi de 38,7\%, ligeiramente superior à do ano anterior, sendo a segunda mais alta da série histórica, e revelando mais uma vez o quanto o empreendedorismo é presente e sentido no cotidiano de grande parte dos brasileiros (GEM, 2019, p. 10).

$\mathrm{O}$ empreendedor identifica, planeja, cria e elabora novas ideias, aproveitando as oportunidades que o mercado de trabalho oferece. O desenvolvimento de um novo serviço é uma oferta que resulta em uma adição no mix de serviços atuais. Depois de definido, o produto/serviço que será oferecido, deverá ser disposto ao mercado, de forma a se aproximar de seu comprador principal e resultar na satisfação deste cliente.

\subsection{Empreendedorismo feminino}

No começo do século XX, as mulheres alcançaram direitos civis e políticos por meio de lutas sociais proporcionadas pelo seu acesso à educação. A partir dos anos 70 foi redefinida a divisão segundo o gênero no trabalho. Daí em diante, ocorreu 
uma crescente participação da mulher no mercado de trabalho, mas, apesar desse crescimento, ela ainda é pequena em relação à participação dos homens (Lages, 2005).

Segundo o relatório publicado pelo SEBRAE em 2019, foi possível obter dados oferecidos pelo GEM no ano de 2018, onde pode ser observado que o Brasil teve a $7^{\mathrm{a}}$ maior proporção de mulheres entre os empreendedores iniciais do mundo. As mulheres representam cerca de 24 milhões entre os 52 milhões de empreendedores do Brasil (SEBRAE, 2019, p. 3-4).

Conforme dados levantados pela Pesquisa Nacional por Amostra de Domicílios - PNAD (IBGE) em 2018, dos 18,1 milhões de pessoas donas do próprio negócio, cerca de 9,3 milhões de mulheres estão à frente de um negócio (formal ou informal) como empregadora (SEBRAE, 2019, p. 4).

No ano de 2019, houve aproximadamente 53,5 milhões de brasileiros, entre 18 e 64 anos, à frente de alguma atividade empreendedora, envolvidos na criação de novo empreendimento, consolidando um novo negócio ou realizando esforços para manter um empreendimento já estabelecido (GEM, 2019, p. 10).

Conforme o Instituto Rede Mulher Empreendedora, observa-se que 49\% das mulheres abrem um negócio sem nenhum planejamento, $41 \%$ deste público misturam o dinheiro da casa com o do negócio, sem nenhuma percepção financeira adequada (IRME, 2019, p. 10-12).

A necessidade de complementar a renda familiar, a auto realização, a busca por trabalho informal, entre outros motivos, têm levado as mulheres brasileiras a empreenderem, por essa razão, a participação do empreendedorismo feminino no Brasil vem sendo forte (Almeida et al., 2011, p. 112).

A mulher empreendedora está inserida em um cenário onde é necessário atualização constante da sua área de conhecimento e expansão de mercado. Lida com questões sociais, culturais e econômicas: autogestão, responsabilidade social, sustentabilidade, democracia, desenvolvimento econômico, etc. (Cineglaglia et al., 2021).

\subsection{Empreendedorismo feminino no ramo alimentício}

No ano de 2017, 33\% das mulheres empreendedoras investiram em negócios focados em comércio de produtos; $20 \%$ são empreendedoras do ramo alimentício e $12 \%$ investiram na indústria de transformação (SEBRAE, 2019, p. 8).

Para fugir dos altos índices de desemprego, grande parte dos brasileiros optam por abrir seus próprios negócios. Alguns setores são mais resilientes à crise e surgem como boas alternativas para quem deseja empreender, entre eles, pode-se destacar a alimentação. Áreas como fornecimento de comidas prontas, serviço ambulante de alimentos e outros alimentos tradicionais do ramo de alimentação e bebidas conseguem manter ótimas taxas de crescimento. Segundo o IBGE, a alimentação fora de casa consome quase um terço $(32,8 \%)$ do total das despesas das famílias brasileiras (Loschi, 2019).

As atividades relacionadas a gastronomia (restaurantes, lancherias, ambulantes, bares, padarias e assemelhados) estão entre as mais procuradas pelos empreendedores iniciais, ultrapassando $25 \%$ das escolhas de negócios. Entre os empreendedores por necessidade, mais de 50\% escolhem atividades relacionadas aos serviços de alimentação (Klafke, 2017).

\subsection{Empreendedorismo em tempos de pandemia (COVID-19)}

Com a globalização da economia, as empresas estão sendo forçadas a se adaptarem às exigências determinadas pelo mercado de trabalho internacional. A partir desse cenário, aspectos como qualidade, capacidade de adaptação e ganhos com a produtividade se tornaram mais valorizados (Stadler et al., 2014).

Pesquisa realizada pela PNAD Contínua mostra a diferença na taxa de desemprego de homens e mulheres no quarto trimestre de 2020. O percentual foi de 11,9\% entre os homens e 16,4\% entre as mulheres (Barros, 2021).

Os jovens foram os mais afetados pelo desemprego, tiveram taxa acima ou igual à média nacional. Pessoas de 14 a 17 anos, representam 42,7\%, de 18 a 24 anos de idade, 29,8\%, de 25 a 39 anos, 13,9\% (Barros, 2021). 
Para as pessoas com ensino médio incompleto, a taxa de desemprego foi 23,7\%. Para o grupo de pessoas com nível superior incompleto, a taxa foi estimada em $16,9 \%$, mais que o dobro da porcentagem entre aqueles com nível superior completo, 6,9\% (Barros, 2021).

Segundo Vilela, em 2020 o Brasil registrou o maior número de empreendedores de sua história, motivo gerado pelo período pandêmico, e principalmente pela necessidade de geração de renda. Nos nove primeiros meses do ano, o número de micro empreendedores individuais (MEIs) cresceu 14,8\%, na comparação do mesmo período do ano passado, chegando a 10,9 milhões de registros (Vilela, 2020).

De acordo com o SEBRAE, “aproximadamente $25 \%$ da população adulta estarão envolvidos, até o fim do ano, na abertura de um novo negócio ou com uma empresa, com até 3,5 anos de atividade" (Vilela, 2020).

O perfil da mulher empreendedora em 2020, em relação a distribuição geográfica no país, está dividida da seguinte forma: 10,3\% na região Norte, $7 \%$ na região Centro-Oeste, $17,7 \%$ na região Sul, 20,3\% na região Nordeste e 44,7\% na região Sudeste (IRME, 2020, p. 5).

Vilela ainda relata sobre o levantamento realizado na última semana de agosto de 2020, que as vendas online registraram alta entre as micro e pequenas empresas que vêm utilizando canais digitais, como as redes sociais, aplicativos ou internet como plataformas para comercialização de seus produtos ou serviços. Em maio a porcentagem de empresas que faziam uso dos canais digitais, era de 59\%, esse percentual chega a 67\%, havendo um aumento de $8 \%$ até o mês de outubro (Vilela, 2020).

A respeito das mulheres que já pediram crédito, $15 \%$ delas preferem recorrer a um amigo ou familiar e $11 \%$ pedem aumento do limite de cartão de crédito ou realizam empréstimo pessoal. Entre os principais motivos relacionados ao pedido de crédito, $44 \%$ das mulheres relataram que foi ocasionado pela pandemia. Entre as que nunca pediram empréstimo, o motivo principal foi pela percepção de que o negócio é muito pequeno (IRME, 2020, p. 21).

\section{Resultados e Discussão}

A aplicação da pesquisa foi realizada entre os dias 25 a 28 de setembro, na cidade de Itapagipe, município de Minas Gerais. Cidade com população estimada em aproximadamente 15.500 habitantes atualmente. Tem como base uma amostra de 08 mulheres empreendedoras, escolhidas pela plataforma do Instagram.

Logo abaixo será apresentado através de gráficos o perfil das envolvidas na pesquisa, em relação a idade, nível de escolaridade, estado civil, filhos e ganho mensal. Abordando todos os dados coletados durante a realização do estudo em questão.

O Gráfico 1 a seguir representa a idade das envolvidas na pesquisa: 
Research, Society and Development, v. 11, n. 3, e17011326344, 2022

(CC BY 4.0) | ISSN 2525-3409 | DOI: http://dx.doi.org/10.33448/rsd-v11i3.26344

Gráfico 1: Idade das empreendedoras.

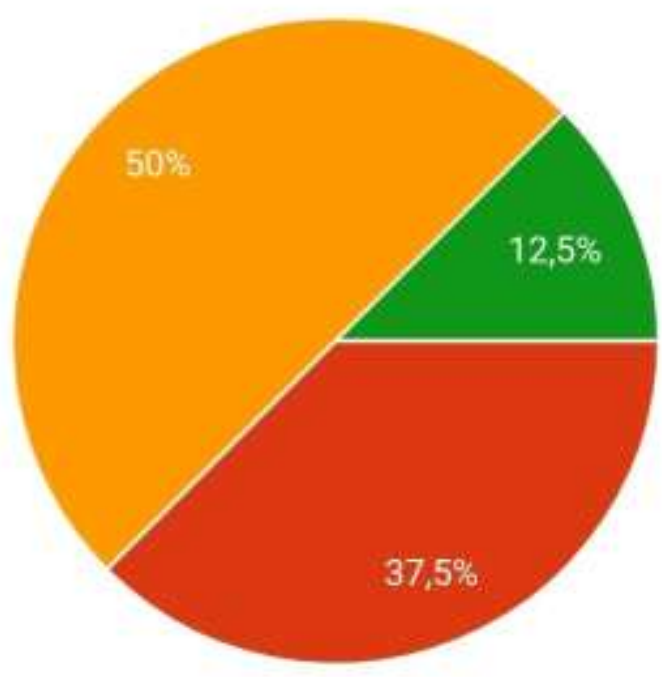

De 15 a 20 anos

De 21 a 30 anos

De 31 a 40 anos

Mais de 40 anos

Fonte: Autores (2021).

No Gráfico 1 é possível perceber que a metade das mulheres possuem entre 31 a 40 anos, 37,5\% são um pouco mais novas, com faixa etária entre 21 a 30 anos e, apenas 12,5\% possuem mais de 40 anos de idade.

O Gráfico 2 diz respeito a qual nível de escolaridade foi possível essas mulheres concluírem:

Gráfico 2: Nível de escolaridade.

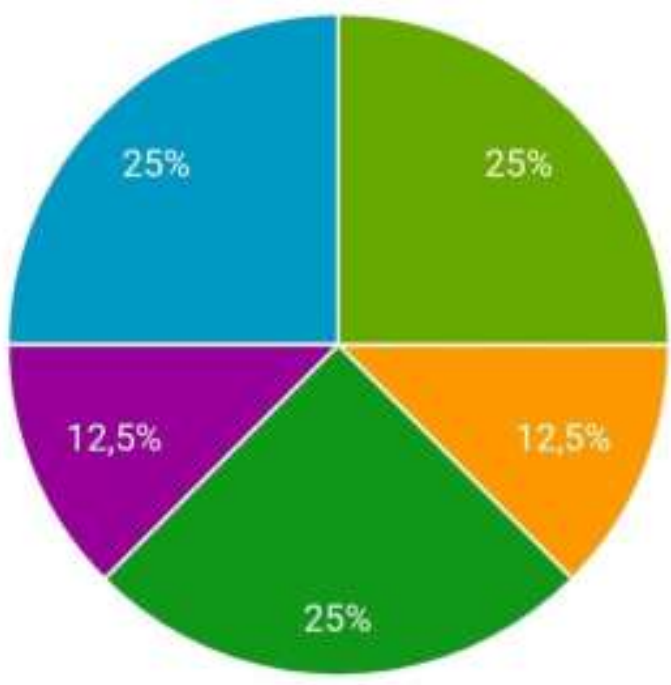

Ensino fundamental incompleto

Ensino fundamental completo

Ensino médio incompleto

- Ensino médio completo

- Ensino superior inc...

Ensino superior co...

Pós-graduação inc...

Pós-graduação co...

Fonte: Autores (2021). 
Research, Society and Development, v. 11, n. 3, e17011326344, 2022

(CC BY 4.0) | ISSN 2525-3409 | DOI: http://dx.doi.org/10.33448/rsd-v11i3.26344

No Gráfico 2 está representado o nível de escolaridade. Há uma igualdade de números entre ensino médio completo, ensino superior completo e pós-graduação completa, sendo $25 \%$ para cada. E $12,5 \%$ para ensino médio incompleto e ensino superior incompleto.

No Gráfico 3 apresenta o estado civil das envolvidas na pesquisa:

Gráfico 3: Estado civil.

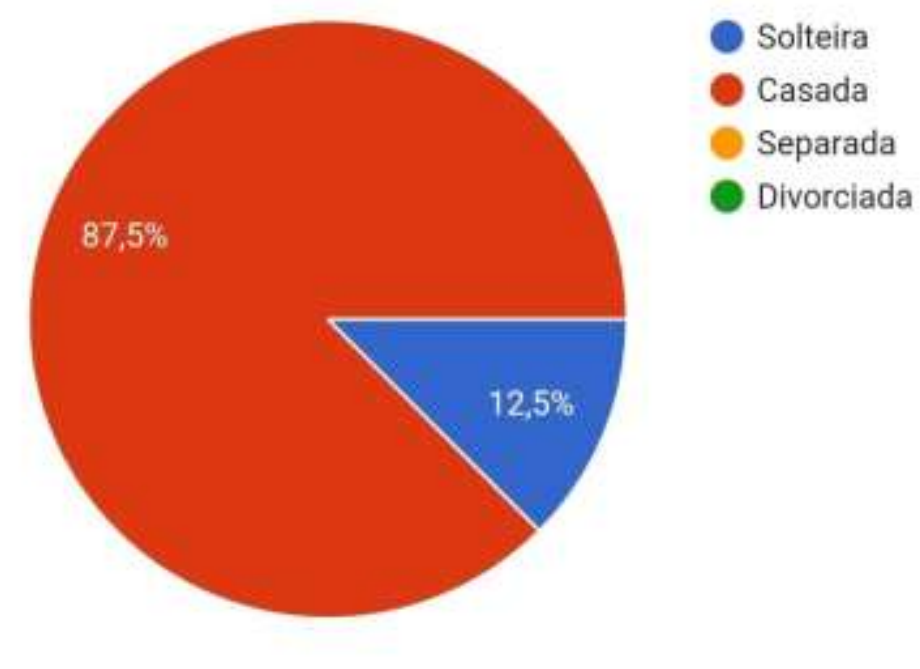

Fonte: Autores (2021).

Em relação ao estado civil, $87,5 \%$ das envolvidas são casadas e vivem com seu marido e, apenas 12,5\% das empreendedoras são solteiras.

No Gráfico 4 é apresentado o resultado referente ao número de filhos: 
Research, Society and Development, v. 11, n. 3, e17011326344, 2022

(CC BY 4.0) | ISSN 2525-3409 | DOI: http://dx.doi.org/10.33448/rsd-v11i3.26344

Gráfico 4: Número de filhos

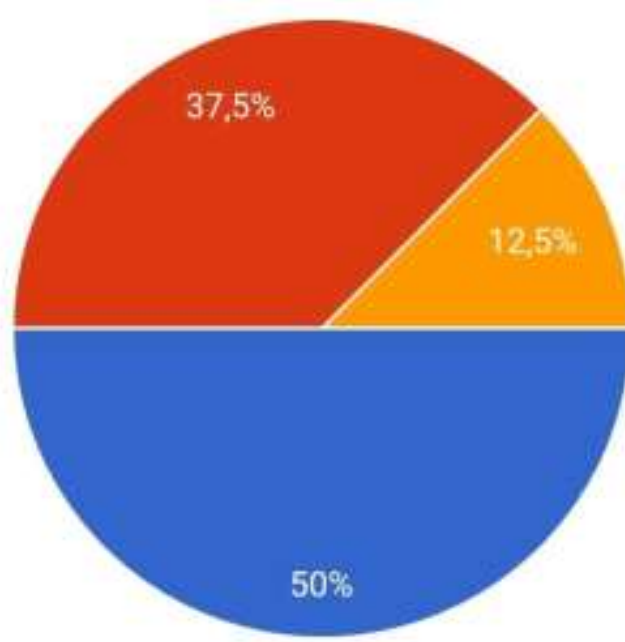

1 filho

2 filhos

3 filhos

Mais de 3 filhos

Fonte: Autores (2021).

O Gráfico 4 apresenta um dado importante em relação as envolvidas, 100\% das mulheres que empreendem possuem filhos, até as que são solteiras. Essa informação é relevante para entender que o papel da mãe é significativo na vida dos filhos, elas precisam disponibilizar tempo, podendo ser considerado um dos motivos pelos quais acarreta uma dificuldade para começar um empreendimento e não conseguir espaço no mercado. O trabalho formal ou informal também serve para suprir as necessidades econômicas de seus descendentes.

O Gráfico 5 corresponde a renda adquirida por mês das empreendedoras:

Gráfico 5: Renda mensal.

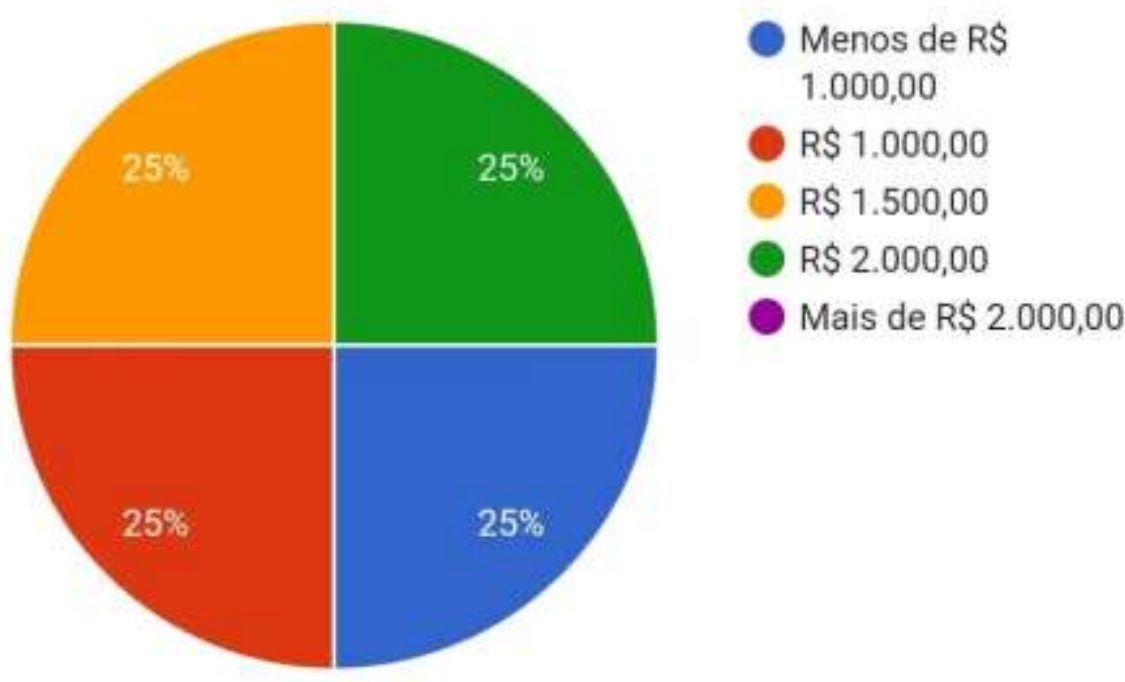

Fonte: Autores (2021). 
Foi feito o levantamento de ganho mensal de cada uma das participantes. O gráfico é dividido da seguinte forma, 25\% possuem uma renda de menos de $\mathrm{R} \$ 1.000,00$ por mês, outros $25 \%$ ganham $\mathrm{R} \$ 1.000,00$, outros $25 \%$ atingem a faixa dos $\mathrm{R} \$$ $1.500,00$ e os outros $25 \%$ faturam $\mathrm{R} \$ 2.000,00$ mensalmente.

Verificou-se alguns motivos pelos quais levaram essas mulheres a seguir esse caminho e abrirem seu próprio negócio. Segue abaixo Quadro 1 com os principais motivos relatados:

Quadro 1: Relatos apresentados.

\begin{tabular}{|c|c|}
\hline $25 \%$ & Ama empreender e estava cansada de trabalhar fora \\
\hline $12,5 \%$ & Provar que é capaz de abrir o seu próprio negócio \\
\hline $12,5 \%$ & Fazer os próprios horários e ter disponibilidade para os filhos \\
\hline $25 \%$ & Aumentar a renda \\
\hline $25 \%$ & Independência, autonomia e traçar as próprias metas \\
\hline
\end{tabular}

Fonte: Autores (2021).

Foi possível perceber que a grande maioria dos relatos foram direcionados ao propósito de ter um ganho extra, maior autonomia e gostar de empreender, podendo ser capazes de traçarem as metas, ter maior disponibilidade de horário com a família e provar que a mulher pode sim empreender e ocupar o seu espaço no mercado de trabalho.

O Gráfico 6 apresenta os dados referente ao questionamento que foi feito para as empreendedoras, sobre a possível citação de alguém que tiveram como exemplo para seguir a carreira:

Gráfico 6: Referência de carreira.

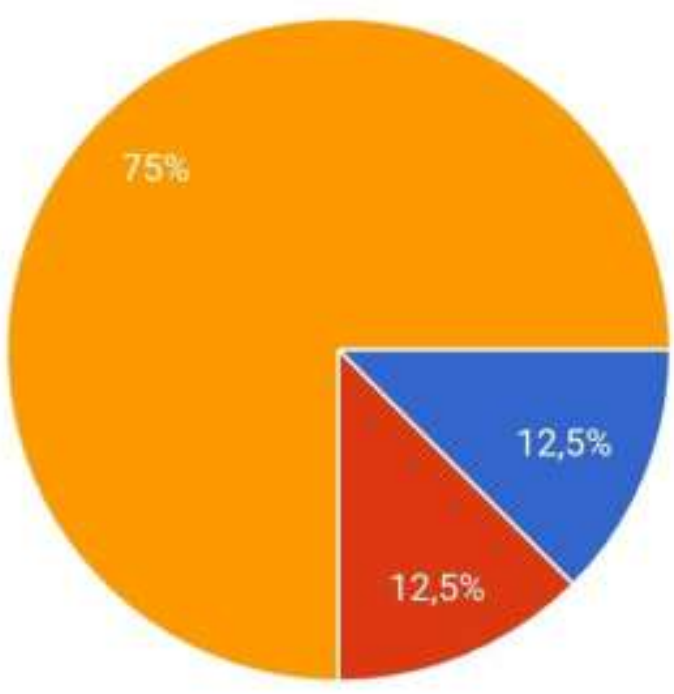

Familiares

Amigos

Năo tive ninguém como referência

Fonte: Autores (2021). 
Foi perguntado para as envolvidas na pesquisa, se tiveram alguma pessoa como modelo, para seguir a carreira de empreendedora. Apenas 25\% responderam que teve sim alguém como referência para seguir essa profissão, $12,5 \%$ representam alguém por laço familiar e os outros $12,5 \%$ por algum amigo próximo. A grande maioria (representando os $75 \%$ ) não teve nenhuma pessoa como referência/espelho para seguir as atividades empreendedoras.

Já o Gráfico 7 é representado com as condições disponíveis que as envolvidas tiveram para abrir seu próprio negócio:

Gráfico 7: Condição estabelecida para abrir o negócio.

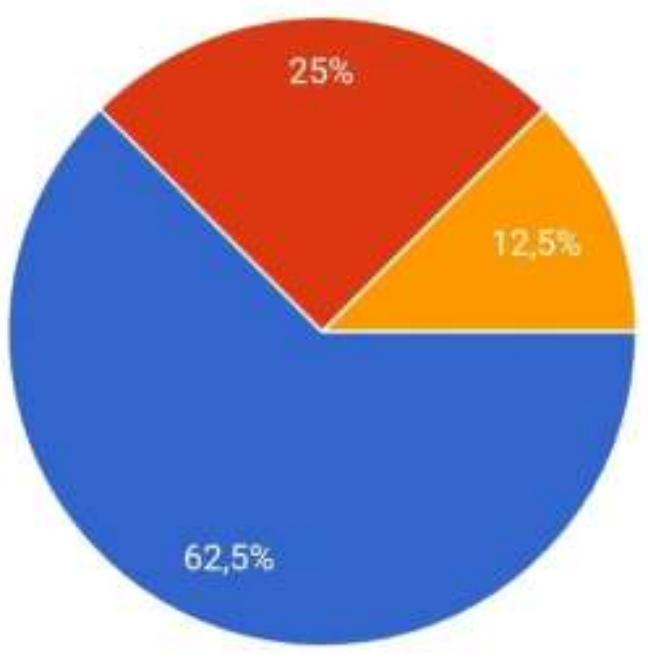

\author{
- Tinha dinheiro \\ guardado/reservado \\ - Peguei dinheiro \\ emprestado com \\ familiares ou \\ amigos \\ Pedi aumento do \\ limite do cartão de \\ crédito
}

Fiz empréstimo pessoal

Fonte: Autores (2021).

Por fim, foi possível observar que a maioria das envolvidas portavam de algum dinheiro guardado ou reservado para abrirem seu negócio, representando 62,5\%. Mas nem todas tiveram essa vantagem, 25\% dessas envolvidas tiveram que pegar dinheiro emprestado com algum familiar ou amigo próximo. Os outros 12,5\% correspondem às mulheres que necessitaram pedir aumento do limite do seu cartão de crédito e, nenhuma precisou fazer algum empréstimo pessoal.

\title{
5. Considerações Finais
}

Pode-se afirmar que a economia brasileira sofreu grandes impactos devido ao coronavírus e, para sobreviver foi preciso reinventar, adaptar e remodelar as ações a serem tomadas em meio às incertezas. Devido a esse fato, assim como muitas empresas vieram a falir ou fechar suas portas, muitos ainda encontraram grandes oportunidades nesse meio.

Com a chegada da crise, muitas mulheres enxergaram novas oportunidades de serviço, em virtude de alguns fatores como, a necessidade de renda familiar, trabalho informal, auto realização profissional, entre outros. Com essas ações, o número de empreendedorismo feminino no Brasil vem crescendo cada vez mais, e esse gênero vai ganhando maior espaço no mercado.

Como foi citado anteriormente, existem duas atividades empreendedoras, empreender por necessidade ou por oportunidade. A primeira diz respeito a pessoas que empreendem por falta de melhores alternativas profissionais e depende mais da situação econômica de um país. Enquanto a segunda envolve maiores chances de sucesso, pode ser planejado e possuir 
de maiores recursos, negócio que se possua outras alternativas na área profissional, podendo alcançar a independência no trabalho.

Contudo, pode-se concluir através dos relatos levantados, que a maioria das envolvidas na pesquisa se enquadram no empreendimento por necessidade. Algumas ainda continuam trabalhando fora e optaram por uma renda extra, enquanto outras trabalham pela oportunidade que tiveram de empreender no ramo alimentício, com tarefas realizadas apenas no seu próprio negócio. Todas as envolvidas utilizam ferramentas online, como Instagram, Facebook e Whatsapp, de modo que o produto chegue e conquiste o consumidor final através das redes sociais.

O presente trabalho possibilita que outros autores adquiriram conhecimentos sobre alguns impactos da pandemia referente a economia, onde a maioria das pessoas tiveram que se reinventar, algumas por oportunidade e outras por necessidade de sustento. Com esse acontecimento a taxa de desemprego teve um aumento, o que possibilitou o crescimento do empreendedorismo no país. Com a pesquisa realizada é capaz de entender um pouco mais sobre o empreendedorismo feminino, de forma que gradativamente as mulheres vêem conquistando maior espaço no mercado de trabalho.

\section{Referências}

Almeida, I. C. \& Antonialli, L. M. \& Gomes, A. F. (2011). Comportamento estratégico de mulheres empresárias: estudo baseado na tipologia de Miles e Snow. p. 112. http://www.spell.org.br/documentos/ver/5785/comportamento-estrategico-de-mulheres-empresarias--estudo-baseado-na-tipologia-de-miles-esnow/i/pt-br.

Barros, A. (2021). Com pandemia, 20 estados têm taxa média de desemprego recorde em 2020. https://agenciadenoticias.ibge.gov.br/agencia-noticias/2012agencia-de-noticias/noticias/30235-com-pandemia-20-estados-tem-taxa-media-de-desemprego-recorde-em-2020.

Cineglaglia, M. N. \& Miranda, M. G. \& Friede, R. \& Cavalcanti, M. T. (2021). Desafios do empreendedorismo feminino no Brasil na atualidade. p. 61. http://lexcultccjf.trf2.jus.br/index.php/LexCult/article/view/544/360.

Degen, R. J. (1989). O empreendedor: fundamentos da iniciativa empresarial. Editora Pearson Education. Ed. 8. São Paulo. p. 15. https://plataforma.bvirtual.com.br/Leitor/Publicacao/1098/pdf/0?code=KRfIDjZNk0u8+bvzTP3m0mRSTCB8MnbrB+R08uZ3owyxKeAko+jSJ/ji+9B2kXNH VNZu69aFd20DqzxYeiZ3tA==.

GEM - Global Entrepreneurship Monitor. (2017). Empreendedorismo no Brasil: Relatório Executivo $2017 . \quad$ p. 9. https://www.sebrae.com.br/Sebrae/Portal\%20Sebrae/Anexos/Relat\%C3\%B3rio\%20Executivo\%20BRASIL_web.pdf.

GEM - Global Entrepreneurship Monitor. (2019). Empreendedorismo no $\quad$ Brasil - $2019 . \quad$ p. $\quad$ 10-15. http://ibqp.org.br/PDF\%20GEM/Relat\%C3\%B3rio\%20Executivo\%20Empreendedorismo\%20no\%20Brasil\%202019.pdf.

Hapsari, N. R. \& Soeditianingrum, N. (2018). Cultural Factors on Female Entrepreneurship: A Literature Review. p. 1. https://www.e3sconferences.org/articles/e3sconf/pdf/2018/48/e3sconf_icenis18_11018.pdf.

IRME - Instituto Rede Mulher Empreendedora. (2019). Empreendedorismo no Brasil: Um recorte de gênero. p. 10-12. https://institutorme.org.br/pesquisas/.

IRME - Instituto Rede Mulher Empreendedora. (2020). Empreendedoras e seus negócios em 2020: Recorte dos impactos da pandemia. p. 5-21. https://institutorme.org.br/pesquisas/.

Klafke, R. (2017). Necessidade X Oportunidade: Empreendedores na Gastronomia. https://sebraers.com.br/alimento/necessidade-X-oportunidade-osempreendedores-na-gastronomia/

Lacerda, M. R. F. (2020). Microempreendedoras individuais diante da pandemia da Covid-19: Como lidar com as incertezas. p. 8. https://repositorio.ufpb.br/jspui/bitstream/123456789/19562/1/MRFL22022021.pdf.

Lages, S. R. C. (2005). Desafios do empreendedorismo feminino: Uma reflexão sobre as dificuldades das mulheres pobres na condução de projetos geradores de renda. p. 3. https://portaladm.estacio.br/media/4404/4-desafios-empreendorismo-feminino-reflexao-dificuldades-mulheres-pobres-conducao-projetosgeradores-renda.pdf.

Loschi, M. (2019). Comer fora de casa consome um terço das despesas das famílias com alimentação. https://agenciadenoticias.ibge.gov.br/agencianoticias/2012-agencia-de-noticias/noticias/25607-comer-fora-de-casa-consome-um-terco-das-despesas-das-familias-com-alimentacao.

Lüdke, M. \& André M. E. D. A. (1986). Pesquisa em educação: Abordagens qualitativas. Editora Pedagógica e Universitária Ltda. São Paulo. p. 11. https://moodle.ufsc.br/pluginfile.php/2431625/mod_resource/content/1/Pesquisa\%20em\%20Educa\%C3\%A7\%C3\%A3o\%20Abordagens\%20Qualitativas\%20 vf.pdf.

Maximiano, A. C. (2011). Administração para empreendedores: Fundamentos da criação e da gestão de novos negócios. Editora Pearson Education. Ed. 2. São $\quad$ Paulo. 1-6. https://plataforma.bvirtual.com.br/Leitor/Publicacao/1994/pdf/0?code=7Rj7gXB165ih0fJOnF1WcLSyhecpe2LuYN5s1OcGh4ct27dAu0gPV1QEgO9ysQzTBy 1GbzxCOXfEH9VkwkiQ2g==. 
Research, Society and Development, v. 11, n. 3, e17011326344, 2022

(CC BY 4.0) | ISSN 2525-3409 | DOI: http://dx.doi.org/10.33448/rsd-v11i3.26344

Stadler, A. \& Arantes, E. C. \& Halicki, Z. (2014). Empreendedorismo e responsabilidade social. Editora InterSaberes. Ed. 2. Curitiba. p. 46. https://plataforma.bvirtual.com.br/Leitor/Publicacao/6096/pdf/0?code=WmwfApZ4xctD84Wo4BHv8Xdup28rd1Mzfh+k333BDU/zSTWSfIfGhRtZ344NCPP sOKs0g/yUxeYvIASnRigPvg==.

SEBRAE. (2019). Empreendedorismo feminino como tendências de negócios: Empreendedorismo feminino em números. p. 8. https://m.sebrae.com.br/Sebrae/Portal\%20Sebrae/UFs/BA/Anexos/Empreendedorismo_feminino_como_tend\%C3\%AAncia_de_neg\%C3\%B3cios.pdf.

SEBRAE. (2019). Empreendedorismo feminino no Brasil. p. 3-4. https://datasebrae.com.br/wp-content/uploads/2019/03/Empreendedorismo-Feminino-noBrasil-2019_v5.pdf.

Soares, B. M. (2020). Atuação do Sebrae junto às empresas e empreendedores no enfrentamento da crise da Covid-19. p. 6. https://bdm.ufmt.br/bitstream/1/1815/1/TCC_2021_Brenda\%20Marques\%20Soares.pdf.

Vilela, P. R. (2020). Pandemia faz Brasil ter recordes de novos empreendedores. https://agenciabrasil.ebc.com.br/economia/noticia/2020-10/pandemia-fazbrasil-ter-recorde-de-novos-empreendedores. 